\title{
CORRESPONDENCE
}

\section{COVID-19 and ARDS: the baby lung size matters}

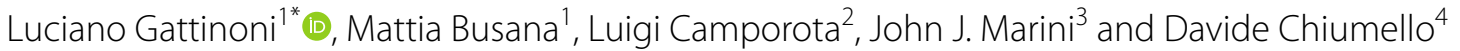

(c) 2020 The Author(s)

We read with interest the editorial by Goligher, Ranieri and Slutsky [1] as it provides an excellent summary of the results of our study on the characteristics of coronavirus disease 2019 (COVID-19) related acute respiratory distress syndrome (ARDS) [2]. The editorialists recognize that our population of patients with severe COVID-19 exhibited anatomical and physiological characteristics that are distinct from the two matched cohorts of typical ARDS. However, they unfortunately fail to comment on our most striking finding, namely the atypically large gas volume of the COVID-19 lung. This feature, and the resulting respiratory compliance, is not analyzed or described in the studies quoted by Goligher et al. but is the key to understanding the distinctive features of COVID-19. Moreover, Ranieri and Slutsky recently published a paper on ARDS pathophysiology [3] which provides data in support of the discordance between respiratory mechanics and oxygenation (see Supplementum, Table S2). Actually, the finding of "flexible lungs" as an early manifestation of COVID-19 is such a common clinical experience that it has been widely reported also by the public media. As repeatedly expressed in our paper, the differences in respiratory mechanics between our cohort and other published cohorts is likely due to the time in which the patients were studied. The "baseline" condition the editorialist refer to may refer to different phases of the disease, especially during the pandemic's first wave, when the access to the intensive care unit was often markedly delayed due to lack of beds in intensive care unit (ICU).

*Correspondence: gattinoniluciano@gmail.com

${ }^{1}$ Department of Anesthesiology, Intensive Care and Emergency Medicine, Medical University of Göttingen, Göttingen, Germany

Full author information is available at the end of the article
Therefore, COVID-19 in its initial manifestations has strikingly peculiar characteristics (e.g., hypoxaemia with vasocentric injury and high gas lung volume), is so evident that atypical ARDS should not be a matter of further discussion. Yet, in an apparent attempt to preserve the concept of "classical" ARDS during their discussion of our data Goligher et al. come to the rather surprising conclusion that it is not the ARDS we observed to be atypical but rather that our patients were atypical for COVID-19 pneumonia.

Beyond the purely semantic arguments, what really matters is the respiratory treatment administered to single individuals. We may wonder if the currently applied protocols guiding ARDS treatment, which were developed on evidence gathered from unselected populations with different etiologies, need to be equally applied without caution to this new, single-etiology disease. For example, a tidal volume of $6 \mathrm{ml} / \mathrm{kg}$ - a standard of care for the ARDS 'baby lung'-is obviously acceptable, although somewhat higher tidal volumes of $7-8 \mathrm{ml} / \mathrm{kg}$ were proven to be not-harmful in randomized controlled trials $[4,5]$. In highly compliant "COVID-19 adult lungs", tidal volumes of 7-8 $\mathrm{ml} / \mathrm{kg}$ may reduce the risk of hypoventilation-induced reabsorption atelectasis, without a significant increase in the risks of ventilator-induced lung injury. Indeed, in this condition, plateau and driving pressures remain well below accepted numerical ARDS thresholds for harm. Similarly, the current protocols for setting positive end expiratory pressure (PEEP) (e.g., $\mathrm{PEEP}-\mathrm{FiO}_{2}$ tables, stress index), in patients with highly compliant lungs may result in hyperinflation and hemodynamic consequences without any reasonable advantage in terms of alveolar recruitment or oxygenation, as also acknowledged by the editorialists.

We believe that COVID-19 teaches us an important lesson: within ARDS (invented by mankind), the diversity of disease expression (generated by Nature) may require

\section{6 Springer}


different ventilatory treatments, depending on how they affect the lung characteristics: what is a protective strategy in one case, may become a potentially devastating strategy in others. We must always remember that COVID-19, an identical disease all over the world, has resulted in dramatically different outcomes (e.g., 20-80\% mortality rates), in different ICUs. The ventilatory treatment may play a substantial role.

\section{Author details}

${ }^{1}$ Department of Anesthesiology, Intensive Care and Emergency Medicine, Medical University of Göttingen, Göttingen, Germany. ${ }^{2}$ Department of Adult Critical Care, Guy's and St Thomas' NHS Foundation Trust, Health Centre for Human and Applied Physiological Sciences, London, UK. ${ }^{3}$ Department of Pulmonary and Critical Care Medicine, University of Minnesota and Regions Hospital, St. Paul, Minnesota, USA. ${ }^{4}$ Department of Anesthesiology and Intensive Care, ASST Santi e Paolo Hospital, University of Milan, Milan, Italy.

\section{Funding}

Open Access funding enabled and organized by Projekt DEAL.

\section{Compliance with ethical standards}

\section{Conflicts of interest}

The authors disclose no conflicts of interest.

\section{Open Access}

This article is licensed under a Creative Commons Attribution-NonCommercial 4.0 International License, which permits any non-commercial use, sharing, adaptation, distribution and reproduction in any medium or format, as long as you give appropriate credit to the original author(s) and the source, provide a link to the Creative Commons licence, and indicate if changes were made. The images or other third party material in this article are included in the article's Creative Commons licence, unless indicated otherwise in a credit line to the material. If material is not included in the article's Creative Commons licence and your intended use is not permitted by statutory regulation or exceeds the permitted use, you will need to obtain permission directly from the copyright holder. To view a copy of this licence, visit http://creativecommons.org/licen ses/by-nc/4.0/.

\section{Publisher's Note}

Springer Nature remains neutral with regard to jurisdictional claims in published maps and institutional affiliations.

Accepted: 11 November 2020

Published online: 4 December 2020

\section{References}

1. Goligher EC, Ranieri VM, Slutsky AS (2020) Is severe COVID-19 pneumonia a typical or atypical form of ARDS? And does it matter? Intensive Care Med. https://doi.org/10.1007/s00134-020-06320-y

2. Chiumello D, Busana M, Coppola S, Romitti F, Formenti P, Bonifazi M, Pozzi T, Palumbo MM, Cressoni M, Herrmann P, Meissner K, Quintel M, Camporota L, Marini JJ, Gattinoni L (2020) Physiological and quantitative CTscan characterization of COVID-19 and typical ARDS: a matched cohort study. Intensive Care Med 46(12):2187-2196. https://doi.org/10.1007/ s00134-020-06281-2

3. Grasselli G, Tonetti T, Protti A, Langer T, Girardis M, Bellani G, Laffey J, Carrafiello G, Carsana L, Rizzuto C, Zanella A, Scaravilli V, Pizzilli G, GriecoDL Di Meglio L, de Pascale G, Lanza E, Monteduro F, Zompatori M, Filippini C, Locatelli F, Cecconi M, Fumagalli R, Nava S, Vincent JL, Antonelli M, Slutsky AS, Pesenti A, Ranieri VM; collaborators (2020) Pathophysiology of COVID19-associated acute respiratory distress syndrome: a multicentre prospective observational study. Lancet. Respir Med. 27:S2213-2600(20)30370-2. https://doi.org/10.1016/S2213-2600(20)30370-2

4. Stewart TE, Meade MO, Cook DJ, Granton JT, Hodder RV, Lapinsky SE, Mazer CD, McLean RF, Rogovein TS, Schouten BD, Todd TR, Slutsky AS (1998) Evaluation of a ventilation strategy to prevent barotrauma in patients at high risk for acute respiratory distress syndrome. Pressure- and volume-limited ventilation strategy group. N Engl J Med 338:355-361

5. Brower RG, Shanholtz CB, Fessler HE, Shade DM, White P Jr, Wiener CM, Teeter JG, Dodd-o JM, Almog Y, Piantadosi S (1999) Prospective, randomized, controlled clinical trial comparing traditional versus reduced tidal volume ventilation in acute respiratory distress syndrome patients. Crit Care Med 27:1492-1498 